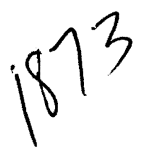

\title{
LIVER AND INTESTINE TRANSPLANTATION
}

Jorge Reyes, MD, Satoru Todo, MD, and Thomas E. Starzl, MD, PhD

\section{LIVER TRANSPLANTATION}

Transplantation of the liver, as originally conceived, was first reported in 1955 as an auxiliary liver transplant in which the native liver was preserved in its normal position and the new liver placed at a heterotopic site, usually the right paravertebral gutter, with portal inflow supplied with systemic blood via the inferior vena cava or iliac vein. Orthotopic liver transplantation is the accepted procedure today. The native liver is removed and replaced by a liver allograft in its normal location. The most common type of transplantation encompasses five anastomoses: the suprahepatic vena cava, the infrahepatic vena cava, the portal vein, the hepatic artery, and the biliary reconstruction.

\section{Indications for Liver Transplantation}

The indications for liver transplantation have evolved concomitantly with all aspects of this field and presently include cirrhosis (posthepatic, alcoholic, autoimmune, cryptogenic), cholestatic liver disease (primary biliary cirrhosis, sclerosing cholangitis, biliary atresia), neoplasm, fulminant hepatic failure, and inborn errors of metabolism. There has been progress in the continuing struggle to identify, treat and prevent a

This work was supported by the Veterans Administration and Project Grant No. DK29961 from the National Institutes of Health, Bethesda, Maryland.

From the University of Pittsburgh, Pittsburgh Transplantation Institute, Children's Hospital of Pittsburgh, Pittsburgh, Pennsylvania

IMMUNOLOGY AND ALLERGY CLINICS OF NORTH AMERICA 
variety of complications to which the liver transplant recipient is subject. These complications may include postoperative bleeding, technical complications with any of multiple vascular and biliary anastomoses, infections, and graft dysfunction.

\section{Advances Made Possible by FK506 (Tacrolimus)}

The struggle to develop clinical liver transplantation to its present status has spanned 3 decades. Advances in organ preservation, surgical techniques, and peri- and postoperative care have been essential components of this success. However, only with improvements in immunosuppressive regimens and treatment of allograft rejection was this parallel evolution translated into acceptable patient survival. With the introduction of cyclosporine in 1980 liver transplantation was expanded to permit universal applicability. It is currently performed in over 100 institutions in the United States alone, as well as Europe; efforts to institute transplantation programs in South America and Asia are well beyond the developmental stage. By 1989, 1,835 patients had been transplanted at our center under cyclosporine and prednisone based immunosuppression. ${ }^{38,47}$ After 3 years of pre-clinical research, a clinical trial of FK506 (tacrolimus) for orthotopic liver transplantation was begun in February 1989: First as rescue therapy for patients with intractable rejection under conventional immunosuppression, then as part of a randomized trial comparing tacrolimus to conventional immunosuppression, and finally as a primary drug.

\section{Initial Clinical Studies with Tacrolimus}

The clinical application of tacrolimus began after extensive laboratory research in Chiba, Pittsburgh, and Cambridge. In February 1989 it was used successfully to salvage 8 of 10 liver allograft recipients suffering intractable rejection despite optimal cyclosporinebased immunotherapy. ${ }^{50}$ Further use for this indication accrued over 200 patients, and was expanded to include recipients of heart, kidney, lung, and pancreas allografts. ${ }^{10,12}$ In the patients whose graft dysfunction was attributed to acute or the early stages of chronic rejection the success rate has been as high as $90 \%$, and even with chronic rejection of the liver salvage has approached $50 \% .^{12}$

\section{Randomized Clinical Trials with Tacrolimus}

After the positive experience with the rescue patients, clinical trials using tacrolimus as the primary immunosuppressive agent for recipients of liver, kidney, and thoracic organs were initiated. ${ }^{46,55}$ Although there was clear evidence of drug superiority with our initial cohort of recipients, an Institutional Review Board (IRB) mandated trial was begun in February 1990 which included a total of 79 low risk patients. In Decem- 
ber 1991, this trial was discontinued after recommendations from a multi-institutional "Patient's Rights Committee," with the concurrence of the IRB and the Food and Drug Administration (FDA).

In the Pittsburgh randomized trial all treatment variables were equal including a daily dose of $20 \mathrm{mg}$ prednisone. The occurrence of rejection, and the need to treat with added prednisone or other adjuvant therapy directly reflected the efficacy of the competing drugs. With the "intention to treat analysis" (crediting the end-point outcome to the original assigned randomization), the one year patient survival was $94 \%$ tacrolimus versus $89 \%$ cyclosporine, and graft survivals were $98 \%$ tacrolimus versus $80 \%$ cyclosporine. ${ }^{11}$ However, at the end of $31 / 2$ years the composite freedom from rejection, or graft loss (death or retransplantation) was $24 \%$ for tacrolimus versus $8 \%$ for cyclosporine. Freedom from "adverse events" was $6 \%$ for tacrolimus versus $1 \%$ for those originally assigned to cyclosporine. Freedom from rejection alone was seen in $33 \%$ of patients in the tacrolimus cohort compared to $12 \%$ for the cyclosporine cohort. At the end of 1 year 51 of the 75 patients originally assigned to receive cyclosporine had been converted to tacrolimus. It was concluded that tacrolimus was superior to cyclosporine A. ${ }^{11}$

Different although generally congruent information was produced by the European ${ }^{27}$ and American ${ }^{5}$ multi-center trials which supported commercial release of tacrolimus by the FDA in June 1994. In the European study, although patient and graft survival rates were not significantly different (tacrolimus $82.9 \%$ and $77.5 \%$ versus cyclosporine $77.5 \%$ and $72.6 \%$, respectively), the use of tacrolimus was associated with a significant reduction in acute, refractory acute, and chronic rejection episodes. Although the survival advantage was not statistically significant it was noted that $10 \%$ of the surviving grafts credited to cyclosporine had been rescued with tacrolimus. Toxicity variables were similar and comparable. ${ }^{27}$ In the American study, actuarial patient and graft survivals were comparable. It was noted that although tacrolimus was associated with significantly lower episodes of acute and refractory rejection there were substantially more toxic events requiring discontinuation of tacrolimus. ${ }^{5}$ However, reanalysis of this data reveals that the composite freedom from refractory rejection, retransplantation, and death was $80 \%$ for the tacrolimus arm versus $70 \%$ for the cyclosporine cohort. ${ }^{45}$

\section{Primary Therapy with Tacrolimus}

Our clinical experience spans 1,391 consecutive adult and pediatric recipients of primary liver allografts treated with tacrolimus between August 1989 and December 1993. ${ }^{56}$ The patient characteristics are summarized in Table 1 . Among these 1,391 recipients $85.4 \%$ were adults and $14.6 \%$ were children. Of the adult patients $26 \%$ were over 60 years of age. The most common indication for transplantation was biliary atresia in children and post-necrotic cirrhosis in adults. The severity of disease for the majority of the patients was high as defined by the existing United Network for Organ Sharing (UNOS) criteria: (1) working; (2) 
Table 1. CHARACTERISTICS OF THE 1391 TACROLIMUS PRIMARY LIVER ALLOGRAFT RECIPIENTS

\begin{tabular}{|c|c|}
\hline Total Patient Population & 1391 \\
\hline No. of transplants & 1582 \\
\hline Primary transplantation & 1391 \\
\hline Retransplantation & 191 \\
\hline Median follow-up months (range) & $26.6(3-55)$ \\
\hline \multicolumn{2}{|l|}{ Pediatric (< 18 yrs) } \\
\hline Number of patients & 203 \\
\hline Mean age $\pm S D$ & $5.4 \pm 5.5$ \\
\hline \multicolumn{2}{|l|}{ Indications } \\
\hline Fulminant failure & $13(6.4 \%)$ \\
\hline Postnecrotic cirrhosis & $21(10.3 \%)$ \\
\hline Biliary atresia & $99(48.8 \%)$ \\
\hline Metabolic disease & $27(13.3 \%)$ \\
\hline Primary malignancy & $1(0.5 \%)$ \\
\hline Other & $42(20.7 \%)$ \\
\hline \multicolumn{2}{|l|}{ UNOS Status } \\
\hline 1 & $3(1.5 \%)$ \\
\hline 2 & $57(28.1 \%)$ \\
\hline 3 & $72(35.5 \%)$ \\
\hline 4 & $71(35.0 \%)$ \\
\hline \multicolumn{2}{|l|}{ Adult (>18 yrs) } \\
\hline No. of patients & 1188 \\
\hline Mean age $\pm S D$ & $50.1 \pm 12.0$ \\
\hline \multicolumn{2}{|l|}{ Indications } \\
\hline Fulminant failure & $20(2.5 \%)$ \\
\hline Postnecrotic cirrhosis & $749(63.0 \%)$ \\
\hline Cholestatic disease & $200(16.8 \%)$ \\
\hline Metabolic disease & $38(3.2 \%)$ \\
\hline Primary malignancy & $89(7.5 \%)$ \\
\hline Other & $82(6.9 \%)$ \\
\hline \multicolumn{2}{|l|}{ UNOS Status } \\
\hline 1 & $5(0.4 \%)$ \\
\hline 2 & $189(15.9 \%)$ \\
\hline 3 & $476(40.1 \%)$ \\
\hline 4 & $518(43.6 \%)$ \\
\hline
\end{tabular}

home (but requiring close medical supervision and/or sporadic hospital care); (3) hospital-bound continuously; (4) ICU-bound.

\section{Clinical Approach to Liver Transplantation}

\section{Immunosuppression}

Our early clinical experience showed dose related nephrotoxicity, neurotoxicity, and diabetogenicity, which were paralleled with defective metabolism of the drug when there was hepatic graft dysfunction. ${ }^{1}$ These observations prompted progressive dose revisions which were guided by a balance between freedom of rejection, toxicity, and trough plasma levels of tacrolimus measured with an enzyme immunoassay 
technique and targeted to $1 \mathrm{ng} / \mathrm{mL}$. Our present policy is to give tacrolimus initially intravenously as a continuous infusion at a dose of $0.05 \mathrm{mg} / \mathrm{kg} /$ day. The conversion from intravenous to oral therapy is usually made with a small overlap at a starting oral dose of $0.1-0.15$ $\mathrm{mg} / \mathrm{kg}$ every 12 hours.

The steroid administration involved 1 gram of methylprednisolone given intravenously immediately after graft reperfusion, followed by a 5 day burst of methylprednisolone which was started at $200 \mathrm{mg}$ on the first day and reduced to a baseline of $20 \mathrm{mg}$ /day on post-operative day 6. Appropriately lower doses were given in infants and children. In a subsequent phase, the 5 day burst therapy was replaced with a standard $20 \mathrm{mg} /$ day of methylprednisolone, the initial high dose steroid burst being reserved for positive lymphocytotoxic cross matches..$^{52}$ With either regimen, steroids were weaned over several months and eventually stopped if there was no evidence of rejection.

Clinical diagnosis of rejection was confirmed by a needle biopsy. Initial therapy for rejection included optimization of maintenance tacrolimus levels and bolus therapy with methylprednisolone or hydrocortisone. Persistence of rejection was treated with 5 day burst therapy using methylprednisolone. Steroid resistant rejection was treated with a 3 to 5 day course of 5-10 $\mathrm{mg}$ /day of monoclonal antibody to the T cell receptor (OKT3). Azathioprine (0.5-2 mg/ $\mathrm{kg} /$ day) was given in cases of recurrent rejection or evidence of clinical toxicity necessitating the reduction of tacrolimus trough levels.

Patient survival was calculated from the date of transplantation until patient death, and graft survival was calculated from the date of transplantation until retransplantation or patient death. Survival curves were generated using the life table method.

\section{Results}

With a mean follow-up of 29.6 months (range: 3-55), the overall patient actuarial survival rates in children were $91.1 \%, 89.6 \%, 88.5 \%$, $88.5 \%$, and $86.2 \%$, at $3,6,12,24$, and 48 months, respectively, and in adults were $89.7 \%, 86.6 \%, 82.1 \%, 77.7 \%$, and $71.4 \%$, at $3,6,12,24$, and 48 months, respectively (Fig. 1). There were a total of 1,582 liver allografts. The overall graft survival in children was $81.4 \%, 80.1 \%, 79.1 \%$, and $77.0 \%$ at $3,6,12$ and 48 months, respectively, and in adults were $80.3 \%, 76.5 \%, 72.0 \%$, and $61.5 \%$ at $3,6,12$, and 48 months, respectively (Fig. 2). The causes for primary graft failure due to rejection were only 18 grafts $(1.5 \%)$ seen in only the adult population. Greater than $50 \%$ of these liver recipients were rejection free. Nearly half of the adult recipients and over $90 \%$ of the pediatric recipients were steroid free by 3 months after transplantation. Retransplantation was required in $9.9 \%$ of pediatric recipients and $9.8 \%$ of adult recipients (Table 2). The difference between patient and graft survival emphasizes the survival benefit of retransplantation.

Death was attributable to either technical failure (mostly hepatic 


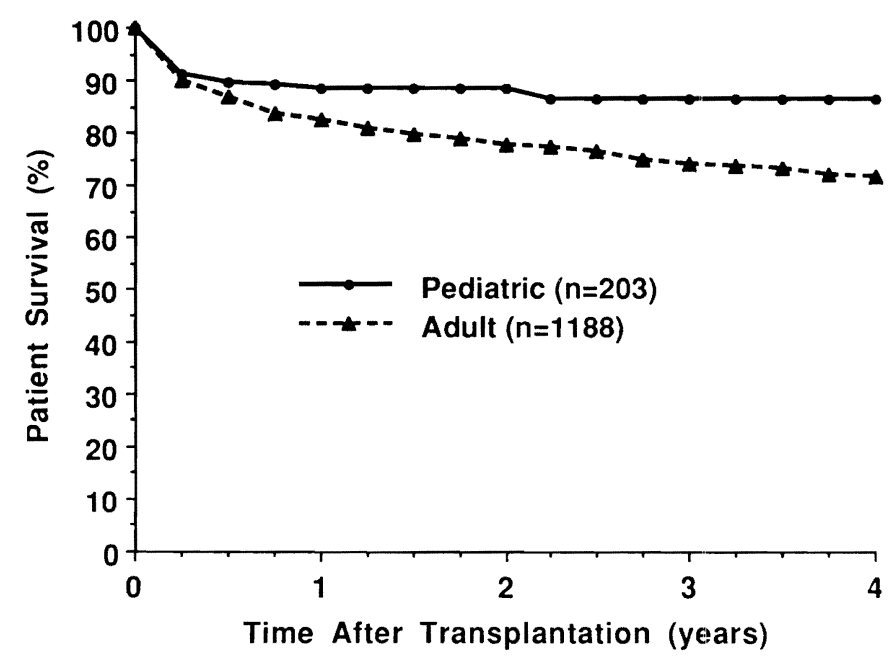

Figure 1. Patient survival for primary liver allograft recipients who received FK506 (Tacrolimus) as the primary immunosuppressive drug therapy.

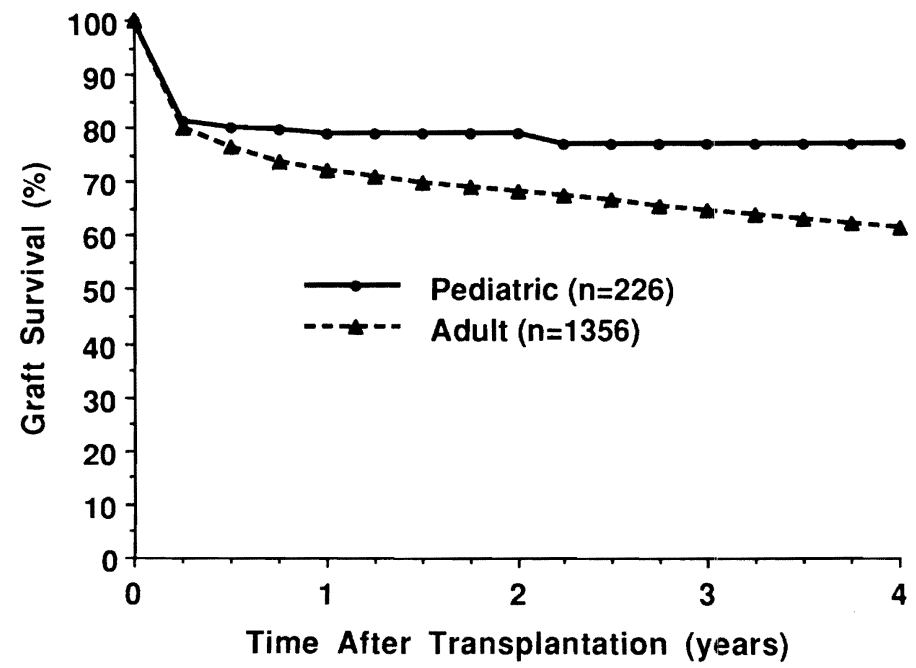

Figure 2. Overall graft survival using FK506 (Tacrolimus) as the primary immunosuppressive drug therapy. The difference between patient and graft survival emphasizes the survival benefit of retransplantation. 
Table 2. INCIDENCE AND CAUSE OF RETRANSPLANTATION OF PRIMARY GRAFT

$\begin{array}{ll}\text { Pediatric Patients } & \\ \text { No. of patients } & 203 \\ \text { No. of retransplantations } & 20(9.9 \%) \\ \text { Causes } & 6(3.0 \%) \\ \text { Technical failure } & 0 \\ \text { Rejection } & 1(0.5 \%) \\ \text { Graft infection } & 13(6.4 \%) \\ \text { Graft failure } & 0 \\ \text { Disease recurrence } & 0 \\ \quad \text { Other } & 1188 \\ \text { Adult Patients } & 116(9.8 \%) \\ \text { No. of patients } & \\ \text { No. of retransplantations } & 28(2.4 \%) \\ \text { Causes } & 7(0.6 \%) \\ \quad \text { Technical failure } & 76(6.4 \%) \\ \text { Rejection } & 2(0.2 \%) \\ \text { Graft failure } & 3(0.3 \%) \\ \text { Other } & 0 \\ \text { Graft infection } & \end{array}$

artery thrombosis, or bile duct complications), sepsis, and immunologically related complications which included rejection, graft-versus-host disease (GVHD), and posttransplant lymphoproliferative disorders (PTLD) (Table 3).

Other aspects of our experience with drug toxicity, drug interactions, opportunistic infections, and other clinical observations have been published elsewhere. ${ }^{3,4,8,16,35}$

\section{INTESTINAL TRANSPLANTATION}

Total parenteral nutrition (TPN) is the standard of care for patients who are unable to maintain a normal nutritional state by the gastrointestinal tract alone. Transplantation of the intestine either alone or accompanied by other intra-abdominal organs (liver, stomach, pancreas, colon) may be beneficial in these patients. Loss of intestinal function may be attributed to loss of bowel length after resections for atresias, infarctions (volvulus, vascular catastrophes, necrotizing enterocolitis), or strictures and fistulas as with Crohn's disease and radiation enteritis. When the anatomic length and gross morphology of the intestine is normal, the functional loss can be attributed to motility disorders (intestinal pseudoobstruction, Hirschsprung's disease), absorptive insufficiencies (microvillus inclusion disease), polyposis syndromes, and incarcerated tumors.

A multi-disciplinary team must assess the baseline disease as well as the severity of other co-morbid states, particularly liver failure and its accompanying gamut of complications. Appropriate selection of candidates and optimization of preoperative morbid conditions (infection, 
Table 3. INCIDENCE AND CAUSE OF MORTALITY

\begin{tabular}{ll}
\hline Pediatric Patients & \\
No. of Patients & 203 \\
No. of mortalities & $18(8.9 \%)$ \\
Causes & $6(3.0 \%)$ \\
Technical failure & $1(0.5 \%)$ \\
Sepsis & $1(0.5 \%)$ \\
Immunusuppression related & $3(1.5 \%)$ \\
Extrahepatic event & 0 \\
Disease recurrence & $7(3.4 \%)$ \\
Graft failure & 0 \\
Other & 1188 \\
Adult Patients & $119(10.1 \%)$ \\
No. of Patients & $22(1.9 \%)$ \\
No. of mortalities & $33(2.8 \%)$ \\
Causes & $9(0.8 \%)$ \\
Technical failure & $1(0.1 \%)$ \\
Sepsis & $33(2.8 \%)$ \\
Immunosuppression related & $1(0.1 \%)$ \\
Other & $20(1.7 \%)$ \\
Graft failure & \\
Disease recurrence &
\end{tabular}

malnutrition) can have a major impact on outcome. Critically ill patients should be excluded. Multiple previous abdominal surgery is not a contraindication for transplantation.

\section{Early Experimental and Clinical Studies}

Experimental and clinical intestinal transplantation have been through several developmental phases over the last 30 years. ${ }^{21,48}$ Success remained blurred because of a high incidence of graft loss due to infection, technical complications and rejection. Rejection and the predicted counterpart of GVHD were two problems that were expected with intestinal transplantation.

Two events helped bring intestinal transplantation to the forefront of clinical practice. First was the demonstration in clinical liver transplantation of the greater efficacy of tacrolimus as described in the previous section. Then, recent laboratory and clinical research with intestinal transplantation played a critical role in establishing a generic bi-directional paradigm of transplantation and immunology that is relevant to all organs. ${ }^{17,24,48,59}$

This reassessment began after a series of human applications of the modified form of this operation, which began in 1987 when a 3-year-old girl received a multivisceral abdominal graft that contained the stomach, duodenum, pancreas, small bowel, colon, and the liver. She had an extended survival of 6 months with good intestinal graft function with- 
out developing either rejection or GVHD. ${ }^{49}$ The cadaveric organs of this recipient were depleted of $\mathrm{T}$ lymphocytes by infusing the donor with OKT3 treatment before procurement and by ex-vivo irradiation after their removal. This type of preconditioning was suspected to have contributed to the wide spread B-cell lymphoma that caused the death of this child. Subsequently 4 more patients achieved functional cadaveric intestinal grafts when transplanted alone ${ }^{14}$ as liver/intestinal composite graft, ${ }^{15,23}$ or as multivisceral allografts. ${ }^{39}$ Only the intestine-alone recipient of Goulet and Revillon ${ }^{14}$ is alive with a functioning graft, while two liver/intestinal recipients of Grant ${ }^{15,23}$ survived for 58 and 66 months. Also, a living related donor intestinal segment was transplanted by Deltz ${ }^{7}$ in February 1988 which supported nutrition for 61 months. All the above transplants were performed under cyclosporine based immunosuppression.

\section{Present Patient Population}

We have performed 71 intestinal transplantations in 67 patients between May 1990 and February 1995. ${ }^{57}$ There were 3 types of intestinal allografts which are shown in Figure 3: isolated intestinal $(n=23)$, combined intestine/liver $(n=32)$, and multivisceral $(n=11)$. Those patients with satisfactory liver function without evidence of portal hypertension received an isolated intestinal allograft. Patients with inborn errors and also TPN induced cholestatic liver disease received a liver plus intestinal allograft. The multivisceral type allograft was indicated in patients who had extensive abnormalities of the entire gastrointestinal tract which included absorptive/secretory, motility, or vascular disorders. The principles and various modifications of these procedures have been described elsewhere. ${ }^{18,51,58,60,61}$ The colon was included as part of the allograft midway through our experience with intestinal transplantation in all 3 recipient cohorts. This was prompted by high post-operative stomal outputs requiring frequent admissions for dehydration.

Our more recent experience also involves including bone marrow infusion at the time of intestinal transplantation. Bone marrow cells were recovered from the same donor as the intestine and were infused intravenously into the recipient in the immediate post-operative period in 4 recent cases ( 3 primary and 1 retransplantation). The rationale for this approach of including simultaneous bone marrow infusion after solid organ transplantation was derived from experimental and clinical evidence that the existence of "chimerism" is critical for graft acceptance. ${ }^{9,26}$

There were 37 children, 16 male and 21 female with a mean age of $4.3 \pm 4.2$ years. Twenty-nine patients were adults, 16 male and 13 female, with a mean age of $33.3 \pm 9.5$ years. The original diseases leading to transplantation are as listed in Table 4 . All patients have been followed through April 1995. Median follow-up was 21 months ranging 


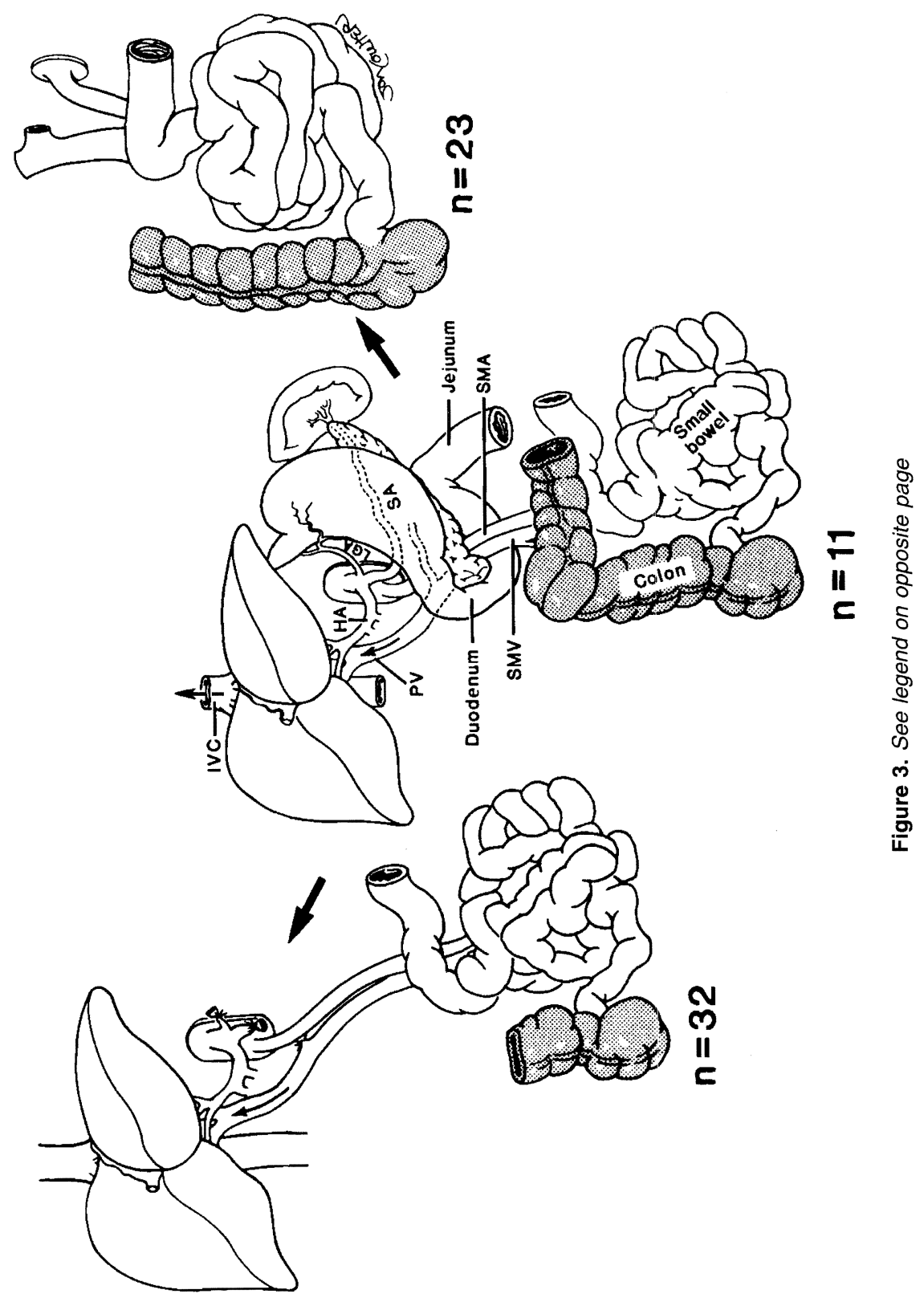


Table 4. CAUSES OF INTESTINAL FAILURE

\begin{tabular}{llll}
\hline \multicolumn{1}{c}{ Children } & \multicolumn{1}{c}{ Adults } \\
\hline Volvulus & 9 & Thrombotic disorder & 8 \\
Gastroschisis & 8 & Crohn's disease & 7 \\
Necrotizing enterocolitis & 6 & Desmoid tumor & 5 \\
Intestinal atresia & 6 & Intestinal trauma & 4 \\
Pseudo-obstruction & 3 & Intestinal adhesions & 2 \\
Microvillus inclusion disease & 3 & Pseudo-obstruction & 1 \\
Intestinal polyposis & 1 & Malignant gastrinoma & 1 \\
Hirschsprung's disease & 1 & Volvulus & 1 \\
Total & 37 & Total & 29 \\
\hline
\end{tabular}

from 1.5 to 57 months. All but 4 of our most recent cohort of recipients have been followed for 1 year post-transplantation.

All donors were cadaveric of the identical $\mathrm{ABO}$ blood type as the recipients. Matching of human leukocyte antigen (HLA) was random and uniformly poor. The lymphocytotoxic cross match was positive in 7 patients. A history of normal intestinal function in a potential liver donation referral is adequate for possible intestinal donation. The procurement of multiple visceral organs focuses on the isolation and cooling of these organs, preserving their vascular and parenchymal anatomy. The organs are flushed with University of Wisconsin (UW) solution. ${ }^{13}$ The cold ischemic time averaged $7.7 \pm 2.4$ hours.

\section{Immunosuppression}

Immunosuppression consisted of tacrolimus and low dose steroids, to which prostaglandin E1 was added briefly during the early postoperative stage. Adjustment of tacrolimus dosing and/or supplemental use of steroids, OKT3, and azathioprine were given for the treatment of rejection episodes. This was based on severity and/or tacrolimus related toxicity as previously described. ${ }^{3}$ Other aspects of toxicity as well as infectious disease complications and complex nutritional management are as described elsewhere. ${ }^{2,36}$

Figure 3. The three types of intestinal allografts: intestine alone (right), liver/intestine (left), and multivisceral (middle). IVC = portal vein; $H A=$ hepatic artery; SMA = superior mesenteric artery; SMV = superior mesenteric vein; SA = splenic artery; LGA = left gastric artery. Colonic segments (shaded) were included in 29 recipients scattered through the three cohorts. (From Todo S, Reyes J, Furukawa H, et al: Outcome analysis of 71 clinical intestinal transplantations. Ann Surg 222:270-282, 1995; with permission.) 


\section{Results of Clinical Trials}

During the potential follow-up of 1 to 5 years and as of April 1995, 32 patients $(48.5 \%)$ are still alive. The actuarial survival rate for the 63 patients at $3,6,12$, and 24 months was $84.1 \%, 80.9 \%, 72.8 \%$, and $57.5 \%$, respectively. The estimated actuarial survival for all types of grafts was $73.5 \%, 70.5 \%, 62.8 \%$, and $48.1 \%$ at $3,6,12$ and 24 months, respectively (Fig. 4). There was no survival difference between the 3 types of transplant procedures or between the pediatric and adult age groups (Fig. 5). Of the 32 surviving patients, 28 still bear their primary allografts which are functional. Only 1 patient requires intermittent night time intravenous hydration. The remaining 4 patients returned to TPN after graft removal and 1 recently underwent a successful retransplantation. Graft survival was similar in adults and children.

Death was the cause of primary graft loss in 35 recipients. Surgical removal of the graft followed by immediate attempted retransplantation occurred in 4 recipients, and there was surgical removal of the graft and return to hyperalimintation in another 4 recipients. The principal reasons for primary graft losses included surgical or clinical management failures which caused the death of the recipient. In 8 recipients the grafts were functioning at or shortly before the time of death. Technical surgical failures were more common in children and included intestinal anastomotic leaks, hepatic artery thrombosis, biliary anastomotic leaks, and cerebral infarction associated with intraoperative cardiac arrest. There was 1 recipient who was non-compliant and developed chronic rejection of the intestinal allograft.

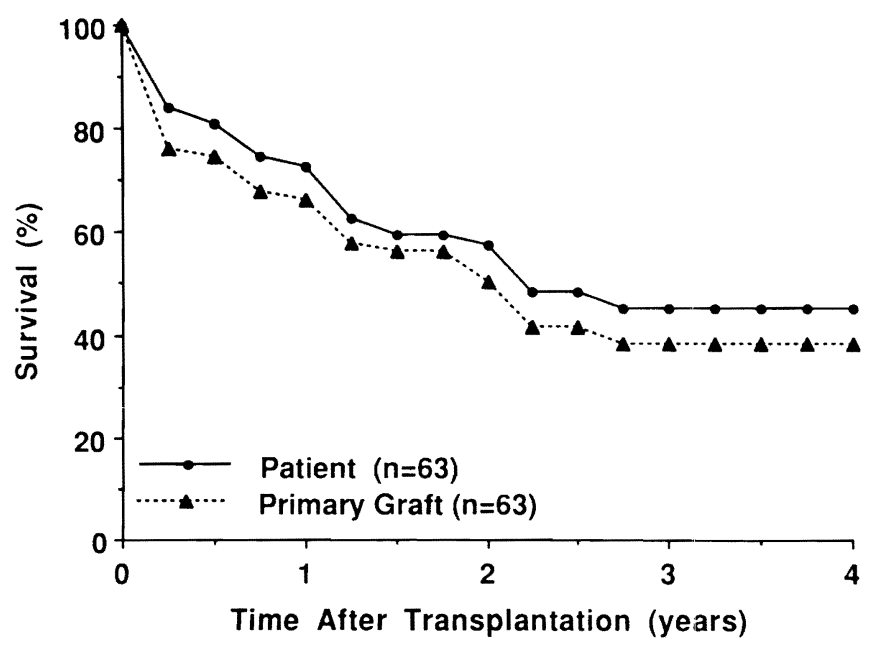

Figure 4. Actuarial patient and allograft survival of the first 63 recipients. (From Todo $\mathrm{S}$, Reyes $\mathrm{J}$, Furukawa $\mathrm{H}$, et al: Outcome analysis of 71 clinical intestinal transplantations. Ann Surg 222:270-282, 1995; with permission.) 


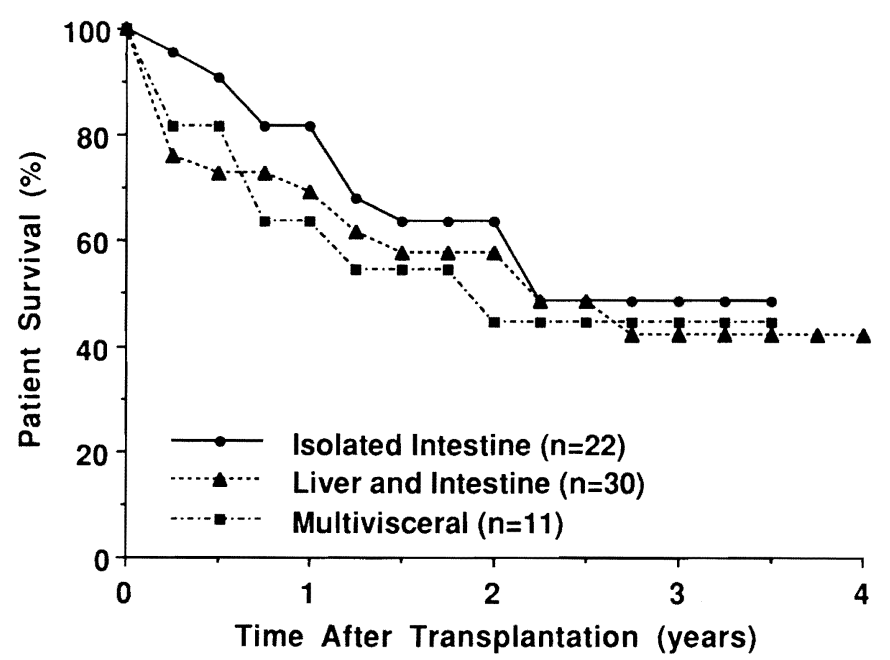

Figure 5. Allograft survival with the three different types of procedures. (From Todo $\mathrm{S}$, Reyes J, Furukawa $\mathrm{H}$, et al: Outcome analysis of 71 clinical intestinal transplantations. Ann Surg 222:270-282, 1995; with permission.)

Reasons for the loss of the other 25 allografts included an array of factors which were interlocking and complex. The principal diagnosis was rejection in only 6 cases, whereas infection as a complication attributable to the immunosuppressive therapy was the major diagnosis in 19 recipients. Bacteria and fungi were accountable for 6 such complications; however, cytomegalovirus (CMV) $(n=5)$ as well as Epstein-Barr virusassociated post-transplant lymphoproliferative disease (PTLD) $(n=12)$ were responsible for significant morbidity. Eight of the 12 patients who developed PTLD died due to this complication.

Retransplantation was performed in 4 patients on the same day as primary graft removal ( 2 liver/intestine) or 1 to 2 months post removal of the primary allograft ( 2 intestinal recipients only). All retransplantated patients died between 47 and 147 days after the second transplant, with the diagnosis of rejection $(n=2)$, PTLD $(n=1)$, and sepsis $(n=1)$. Also, an isolated liver retransplantation was performed in a pediatric recipient who developed thrombosis of the hepatic artery after a combined liver/intestinal graft. A fifth intestinal only retransplantation was carried out in a recipient who had received an intestine only 11 months after graft enterectomy. This patient tolerated retransplantation and was given bone marrow with the second intestinal allograft.

Analysis of these cases has yielded 6 statistically significant risk factors for graft loss and death: high tacrolimus blood trough levels, bolus steroid therapy, OKT3 use for treatment of allograft rejection, length of operation, CMV positive status of donor and recipient, and an inclusion of a segment of colon with the transplanted allograft. The survival of serologically CMV-negative recipients when they receive a 
CMV-negative donor allograft was $62 \%$ versus $47 \%$ when the donor allograft was CMV positive. Also, an adverse effect was noted when the recipient was already CMV positive at transplantation, with a survival of $54 \%$ if the donor allograft was CMV negative, but only $14 \%$ when the donor allograft was CMV positive. The predominant site of CMV disease was the intestinal allograft, and therapy for this disease was marginally effective in these intestinal transplant recipients. Inclusion of a segment of donor colon in the allograft in 29 cases showed a significantly inferior survival than when the colon was not included.

Two of the augmented patients received an isolated intestinal allograft and 2 were given liver plus intestine. One recipient was an isolated intestinal retransplant recipient who had a previous history of PTLD that had been in remission since discontinuance of the immunosuppression and removal of his primary allograft 11 months previously.

Evidence of donor cells was detected in all 4 bone marrow augmented bowel recipients by either PCR and/or flow cytometry. In the female recipient who received a male allograft, presence of donor cells was confirmed by fluorescence in situ hybridization for the $\mathrm{Y}$ chromosome. No evidence of GVHD was found in any of the 4 recipients who were given bone marrow cells.

\section{CHIMERISM AND THE INDUCTION OF GRAFT ACCEPTANCE}

Until recently, insights into the acceptance of a transplanted organ by the recipient immune system were focused on manipulations of the recipient cell population with the use of immunosuppressive drugs. This experience allowed for improved survival after organ transplantation and the development of therapeutic dogmas to which we have adhered tenaciously. Interestingly, most patients progressively require less and less immunosuppressive therapy, and some have discontinued therapy altogether. ${ }^{37}$

Since 1969 it was noted that Kupffer cells and other tissue leukocytes became predominantly of the recipient phenotype within 100 days after transplantation while the hepatocytes retain their donor specificity permanently. ${ }^{19}$ Twenty-two years later other insights emerged regarding allograft acceptance, which were based on the observation that donor leukocytes from transplanted organs had migrated and survived throughout the body of the recipient for as long as three decades. ${ }^{39}, 40$, 43, 44 This process occurred in all successfully transplanted organs, the liver being the most tolerogenic transplanted organ because of its much larger total leukocyte load as well as its lineage profile of the migratory leukocytes. The events following transplantation were then seen as a two way cellular action-graft versus host (GVH) and host versus graft (HVG). Under the cover of immunosuppressive drugs (traffic directors) the graft as well as the recipient become genetic composites composed of cells of both parties (Fig. 6). 


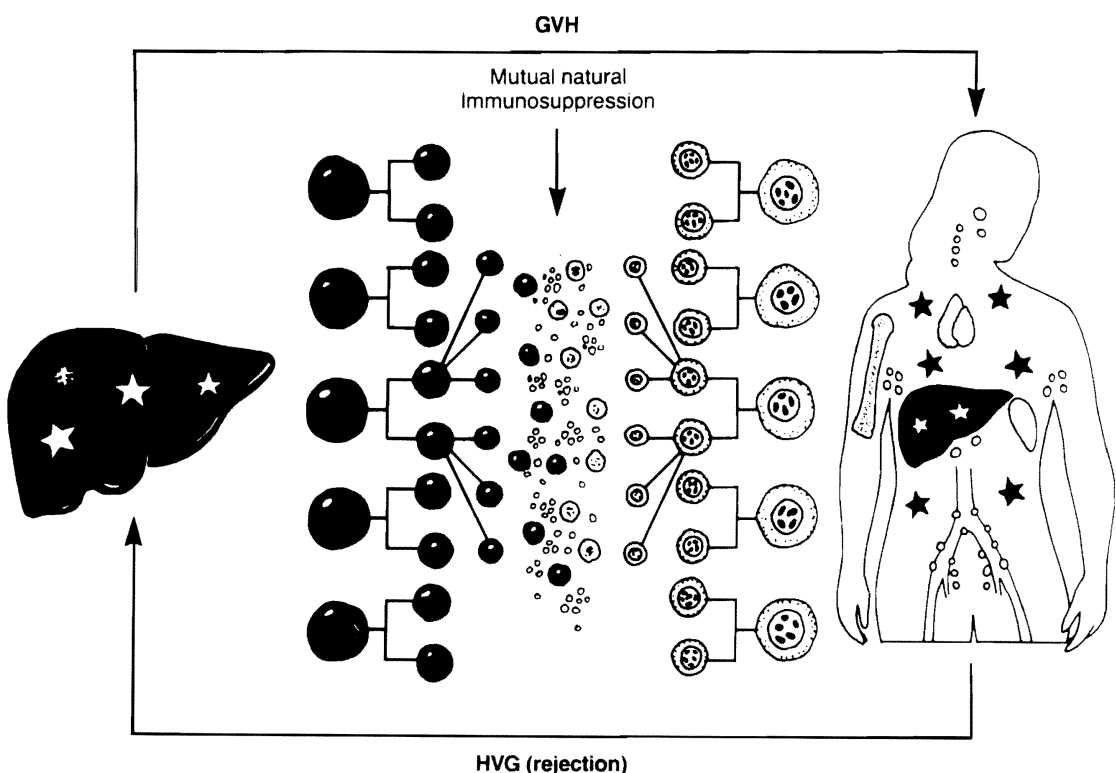

Figure 6. Under the cover of immunosuppressive drugs (traffic directors) there is a mutual engagement of migratory multilineage immunocytes between the graft and the recipient, which become genetic composites composed of cells of both parties. GVH = graft versus host; HVD = host versus graft. (From Starzl TE, Demetris AJ, Murase N, et al: Donor cell chimerism by immunosuppressive drugs: A new view of organ transplantation. Immunol Today 14:326, 1993; with permission.)

This bidirectional migration has been particularly dramatic in all successfully transplanted intestines, and was also observed at different proportions in the liver, kidney, and heart. ${ }^{17,25,31,33}$ Here, since neither the recipient nor the graft is leukocyte depleted, it is possible to routinely perform intestinal and multivisceral transplantation without an exorbitant risk of graft versus host disease (GVHD). This spontaneous "chimerism" after whole organ transplantation differs from bone marrow transplantation in that the treatment strategy involved empirically leaving both cell populations intact. This reciprocal interaction (mutual natural immunosuppression) may blindfold the major histocompatibility complex effect, thus removing tissue matching as a crucial requisite for success, and largely eliminates the threat of GVHD. ${ }^{41}$

Evidence supporting chimerism was found in retrospective studies of long-term survivors of kidney allografts (30 years post-transplantation), liver allografts (10-21 years post-transplantation) and recipients of thoracic organs. ${ }^{42,} 64$ The identity of donor and recipient cells was established after special staining procedures (immunostaining or sex identification after fluorescence in situ hybridization [FISH]), and polymerase chain reaction [DNA fingerprinting]).

The observation of surviving donor multilineage passenger leuko- 
cytes being associated with organ graft acceptance permits us to view the engraftment of any whole organ in the same context as a "mini" bone marrow transplantation. The acceptance of this concept inherently brings about the question of eventually stopping immunosuppressive medication altogether. Many non-compliant patients have stopped their medications sporadically and then completely when all liver functions remained normal. Other patients have had their immunosuppression withdrawn because of infectious complications. ${ }^{37}$ Because complications of immunosuppression have been the principal cause of late death in our long-term surviving recipient population, a prospective, physiciandirected weaning trial was begun. This involved the systematic decrease in the baseline immunosuppression in patients suffering complications of long-term immunosuppression. ${ }^{32}$ Complete weaning was accomplished in 16 patients $(27.1 \%)$ with 3-19 months drug-free follow-up, is progressing in $28(47.4 \%)$, and failed in $15(25.4 \%)$. Patients who failed the weaning trial were restored to their baseline immunosuppression regimen. There were no grafts lost or significant loss of graft function from the rejections. This and our previous experience with patients off immunosuppression indicates that cautious weaning can be performed safely and under careful surveillance 5 to 10 years after transplantation. ${ }^{32}$

The strategy of augmenting this natural migratory traffic would supplement the minimal dose of the passenger leukocytes (which are of bone marrow origin) and thus enhance the natural chimerism. Since March 1993 such a prospective trial has been under way at the University of Pittsburgh by infusing $3 \times 10^{8}$ unaltered donor bone marrow cells (obtained from the thoraco-lumbar vertebrae of the cadaveric donor) perioperatively into an unmodified recipient.9, 34 This trial presently includes 64 patients that have been simultaneously transplanted with donor bone marrow and liver $(n=28)$, liver and islets $(n=1)$, kidney $(n=17)$, kidney and pancreas $(n=2)$, kidney and islets $(n=6)$, heart $(n=8)$, and lungs $(n=8)$. All patients were maintained on routine immunosuppression with tacrolimus and prednisone. Also, 53 recipients of whole organ allografts in whom consent to retrieve donor vertebral column was not available were monitored as contemporaneous controls.

No complication of bone marrow infusion was observed in any of the patients. Four of the 9 kidney/bone marrow recipients were able to come off steroids versus none of the kidney transplant alone recipients. The liver allograft recipients show similar graft function in both groups. All 3 recipients of pancreatic islet cells are currently being maintained on exogenous insulin. Similar episodes of rejection were seen in $58 \%$ of bone marrow-augmented and $64 \%$ of control patients. Asymptomatic GVH reaction in the skin was seen in only 2 patients (recipients of liver/bone marrow), which completely regressed with slight increase in baseline steroid therapy in 1 patient and no therapy in the other. Evidence of circulating donor cells by flow cytometry, PCR, or fluorescence in situ hybridization was present in 18 of 18 study patients and in 9 of 21 control patients. Using in vitro testing by MLR it was possible to 
show evidence of evolving donor-specific hyporeactivity in $41 \%$ of bone marrow augmented patients and $18 \%$ of control patients.

Although all patients are still receiving immunosuppressive therapy, these data suggest that simultaneous infusion of donor bone marrow at the time of whole-organ transplantation may lead to augmentation of chimerism. The timing and eventual progress to a drug-free state remains speculative.

\section{SUMMARY}

The evolution of tacrolimus immunosuppression for recipients of liver allografts has substantiated our belief in the clinical superiority compared to cyclosporine. This was shown in our initial cohort of patients, as well as randomized liver transplant recipients. Results of the multi-center trials conducted in Europe and the United States are congruent with this conclusion. In these randomized trials, crossover from cyclosporine to tacrolimus because of intractable rejection (but not vice versa) was a common event that frequently prevented death or the need for retransplantation. We believe tacrolimus will supplant cyclosporine as the principal baseline immunosuppressive drug for transplantation of the liver and other organs. Not only was there improved patient and graft survivals, but also observed was an improvement in the associated quality of life due to a lower need for steroids, and fewer cosmetic side effects which is of particular importance in the pediatric population.

There is a significantly better understanding of not only the mechanisms of tacrolimus but also of a previous epiphenomenon such as "chimerism," which at the present time we believe is the central event responsible for graft acceptance. The observation of surviving donor multilineage passenger leukocytes being associated with organ graft acceptance implies a persistent engagement of donor and recipient immunocytes with consequent development of various degrees of donor specific non-reactivity. This is of particular importance in recipients of intestinal grafts, where recipient-specific non-reactivity of the chimeric donor cells must occur if the patient is to escape the complication of GVHD.

We are presently armed with a new potent immunosuppressive drug, tacrolimus, and an understanding that the migration and grafting of "passenger leukocytes" of bone marrow origin is the seminal explanation for allograft acceptance. The next forefront will involve manipulation of this process not only for the transplantation of already successful whole organs such as liver, kidney, pancreas and heart, but also in the development of the intestinal transplantation program. Thus, augmentation of the leukocyte traffic of unconditioned recipients of cadaver whole organ allografts by the concomitant intravenous infusion of donor bone marrow cells and under the same conditions of immunosuppressive management of tacrolimus/prednisone treatment will be our path into the future. 


\section{References}

1. Abu-Elmagd K, Fung J, Alessiani M: The effect of graft function on FK506 plasma levels, dosages and renal function, with particular reference to the liver. Transplantation 52:71, 1991

2. Abu-Elmaged K, Fung JJ, Reyes J, et al: Management of intestinal transplantation in humans. Transplant Proc 24:1243-1244, 1992

3. Alessiani M, Cillo V, Fung JJ, et al: Adverse effects of FK506 overdosage after liver transplantation. Transplantation Proc 25:628-634, 1993

4. Alessiani M, Kusne S, Martin M, et al: Infections under FK.506 immunosuppression: Preliminary results with primary therapy. Transplantation Froc 22:44-46, 1990

5. Busuttil RW, McDiarmid S, Klintmalm GB, et al: A comparison of tacrolimus (FK-506) and cyclosporine for immunosuppression in liver transplantation. $\mathrm{N}$ Engl J Med 331(17):1110-1115, 1994

6. Collier DS, Thiru S, Calne R: Kidney transplantation in the dog receiving FK506. Transplant Proc 19(Suppl 6):62, 1987

7. Delz E, Schroeder P, Gebhardt H, et al: Successful clinical small bowel transplantation: Report of a case. Clin Transplant 3:89-91, 1989

8. Eidelman BH, Abu-Elmagd K, Wilson J, et al: Neurological complications of FK506. Transplantation Proc 23:3038-3039, 1991

9. Fontes P, Rao AS, Demetris AJ, et al: Bone marrow augmentation of donor-cell chimerism in kidney, heart, and pancreas islet transplantation. Lancet 344:151-155, 1994

10. Fung JJ, Todo S, Jain A, et al: Conversion of liver allograft recipients with cyclosporine related complications from cyclosporine to FK506. Transplant Proc 26:6-12, 1990

11. Fung JJ, Todo S, Jain A, et al: Single center randomized trial of FK506 versus cyclosporine for liver transplantation. J Am Coll of Surg, in press

12. Fung JJ, Todo S, Tzakis A, et al: Conversion of liver allograft recipients from cyclosporine to FK506-based immunosuppression: Benefits and pitfalls. Transplant Proc 23:14-21, 1991

13. Furukawa H, Abu-Elmagd K, Reyes J, et al: Technical aspects of Intestinal Transplantation. In Braverman MH, Tawes RL (eds): Surgical Technology International II: International developments in surgery and surgical research. Princeton, E.R. Squibb \& Sons, 1993, pp 165-170

14. Goulet O, Revillon $\mathrm{Y}$, Brousse N, et al: Successful small bowel transplantation in an infant. Transplantation 53:940-943, 1992

15. Grant D, Wall W, Mimeault R, et al: Successful small-bowel/liver transplantation. Lancet 335:181-184, 1990

16. Green M, Tzakis A, Reyes J, et al: Infectious complications of pediatric liver transplantation under FK506. Transplantation Proc 23:3038-3039, 1991

17. Iwaki Y, Starzl TE, Yagihashi A, et al: Replacement of donor lymphoid tissue in smallbowel transplants. Lancet 337:818-819, 1991

18. Iwaki Y, Starzl TE, Yagihashi A, et al: Replacement of donor lymphoid tissue in human small bowel transplant under FK506 immunosuppression. Lancet 337:818-819, 1991

19. Kashiwagi N, Porter KA, Penn I, et al: Studies of homograft sex and of gamma globulin phenotypes after orthotopic homotransplantation of the human liver. Surg Forum 20:374-376, 1969

20. Kino T, Hatanaka H, Miyata S, et al: FK 506, a novel immunosuppressant isolated from a streptomyces. II. Immunosuppressive effect of FK 506 in vitro. J Antibiotics 40:1256-1265, 1987

21. Lillehei RC, Miller VA: The physiologic response of small bowel of the dog to ischemia including prolonged in vitro preservation of the small bowel with successful replacement and survival. Ann Surgery 150:543-560, 1959

22. Margreiter R, Konigsrainer A, Schmid T, et al: Successful multivisceral transplantation. Transplant Proc 24:1226-1227, 1992

23. McAlister V, Wall W, Ghent C, et al: Successful small intestine transplantation. Transplant Proc 24:1236-1237, 1992 
24. Murase N, Demetris AJ, Matsuzaki T, et al: Long survival in rats after multivisceral versus isolated small bowel allotransplantation under FK506. Surgery 110:87-98, 1991

25. Murase N, Demetris AJ, Trucco M, et al: Hepatology 17:1127, 1993.

26. Murase N, Zeevi A, Fontes P: Spontaneous and iatrogenically augmented leukocyte chimerism in organ transplant recipients. Transplant Proc 26:3071-3076, 1994

27. Neuhaus $P$, Bechstein WO, Blumhard G, et al: Randomized trial comparing tacrolimus (FK506) and cyclosporin in prevention of liver allograft rejection. Lancet 334:423-428, 1994

28. Ochiai T, Nakajima $K$, Nagata $M$, et al: Effect of a new immunosuppressant agent, FK 506, on heterotopic allotransplantation in the rat. Transplant Proc 19:1284-1286, 1987

29. Ochiai T, Nakajima K, Nagata M, et al: Studies of the induction and maintenance of long-term graft acceptance by treatment with FK506 in heterotopic cardiac allotransplantation in rats. Transplantation 44:734-738, 1987

30. Ochiai T, Sakamoto K, Gunji Y, et al: Effects of combination treatment with FK506 and cyclosporine on survival time and vascular changes in renal allograft recipient dogs. Transplantation 48:193-197, 1989

31. Porter KA: In Starzl TE (ed): Experience in hepatic transplantation. Philadelphia, WB Saunders, 1969, pp 464-465

32. Ramos HC, Reyes J, Abu-Elmagd K, et al: Weaning of immunosuppression in longterm liver transplant recipients. Transplantation 59:212-217, 1995

33. Randhawa PS, Starzl T, Ramos H, et al: Allografts surviving for $26-29$ years following living related kidney transplantation: Analysis by light microscopy, in situ hybridization for the $Y$ chromosome, and anti-HLA antibodies. Am J Kidney Dis 24:72-77, 1994

34. Rao AS, Fontes P, Zeevi A, et al: Augmentation of chimerism in whole organ recipients by simultaneous infusion of donor bone marrow cells. Transplant Proc 27:210-212, 1995

35. Reyes J, Tzakis A, Green M, et al: Posttransplant lymphoproliferative disorders occurring under primary FK506 immunosuppression. Transplantation Proc 23:30443046, 1991

36. Reyes J, Tzakis AG, Todo S, et al: Nutritional management of intestinal transplant recipients. Transplant Proc 25:1200-1201, 1993

37. Reyes I, Zeevi A, Ramos H, et al: The frequent achievement of a drug free state after orthotopic liver transplantation. Transplant Proc, 25:3315-3319, 1993

38. Starzl TE and Demetris AJ: Liver transplantation: A 31 year perspective. Current Problems in Surgery Part I 27:49-116, 1990; Part II 27:117-178, 1990; Part III 27:181240, 1990

39. Starzl TE, Demetris AJ, Murase N, et al: Cell migration, chimerism, and graft acceptance. Lancet 339:1579, 1992

40. Starzl TE, Demetris AJ, Murase N, et al: Donor cell chimerism permitted by immunosuppressive drugs: A new view of organ transplantation. Immunol Today 14:326, 1993

41. Starzl TE, Demetris AJ, Rao AS, et al: Spontaneous and iatrogenically augmented leukocyte chimerism in organ transplant recipients. Transplant Proc 25:3071-3076, 1994

42. Starzl TE, Demetris AJ, Trucco M, et al: Cell migration and chimerism after wholeorgan transplantation: The basis of graft acceptance. Hepatology 17:1127, 1993

43. Starzl TE, Demetris AJ, Trucco M, et al: Chimerism after liver transplantation for Type IV glycogen storage disease and Type I Gaucher's disease. N Eng J Med 328:735, 1993

44. Starzl TE, Demetris AJ, Trucco M, et al: Systemic chimerism in human female recipients of male livers. Lancet 340:876, 1992

45. Starzl TE, Donner A, Eliasziw M, et al: Randomized trialomania?: The multicenter liver transplant trials. Lancet, 2:1346-1350, 1995

46. Starzl TE, Fung J, Jordan M, et al: Kidney transplantation under FK506. JAMA 264:6367, 1990

47. Starzl TE, Iwatsuki S, Van Thiel DH, et al: Evolution of liver transplantation. Hepatology 2:614-636, 1982

48. Starzl TE and Kaupp HA Jr: Mass homotransplantation of abdominal organs in dogs. Surg Forum 11:28-30, 1960

49. Starzl TE, Row $M$, Todo $S$, et al: Transplantation of multiple abdominal viscera. JAMA $261: 1449-1457,1989$ 
50. Starzl TE, Todo S, Fung J, et al: FK506 for human liver, kidney and pancreas transplantation. Lancet 2:1000-1004, 1989

51. Starzl TE, Todo S, Tzakis A, et al: The many faces of multivsiceral transplantation. Surg Gynecol Obstet 172:335-344, 1991

52. Takaya S, Iwaki Y, Starzl TE: Liver transplantation in positive cytotoxic crossmatch cases using FK506, high dose steroids and prostaglandin E1. Transplantation 54:927930, 1992

53. Thiru S, Collier DS, Calne R: Pathological studies in canine and baboon rental allograft recipients immunosuppressed with FK506. Transplant Proc 19(Suppl 6):98-99, 1987

54. Todo S, Demetris AJ, Ueda Y, et al: Canine kidney transplantation with FK506 alone or in combination with cyclosporine and steroids. Transplant Proc 19(Suppl 6):57-61, 1987

55. Todo S, Fung JJ, Starzl TE, et al: Liver, kidney, and thoracic organ transplantation under FK506. Ann Surg 212:295-305, 1990

56. Todo S, Fung JJ, Starzl TE, et al: Single-center experience with primary orthotopic liver transplantation with FK506 immunosuppression. Annals of Surgery 320:297-309, 1994

57. Todo S, Reyes J, Furukawa H, et al: Outcome analysis of 71 clinical intestinal transplantation. Ann Surg 222:270-282, 1995

58. Todo S, Tzakis A, Abu-Elmagd $\mathrm{K}$, et al: Abdominal multivisceral transplantation. Transplantation 59:234-240, 1995

59. Todo S, Tzakis AG, Abu-Elmagd $\mathrm{K}$, et al: Cadaveric small bowel and small bowelliver transplantation in humans. Transplantation 53:369-376, 1992

60. Todo S, Tzakis A, Abu-Elmagd K, et al: Intestinal transplantation in composite visceral grafts or alone. Ann Surg 216:223-234, 1992

61. Todo S, Tzakis A, Reyes J, et al: Small intestinal transplantation in humans with or without colon. Transplantation 57:840-848, 1994

62. Todo S, Ueda Y, Demetris AJ, et al: Immunosuppression of canine, monkey, and baboon allografts by FK506 with special reference to synergism with other drugs, and to tolerance induction. Surgery 104:239-249, 1988

63. Warty V, Diven W, Cadoff E, et al: FK506: a novel immunosuppressive agent: Characteristics of binding and uptake by human lymphocytes. Transplantation 46:453-455, 1988

64. Wilson WEC, Kirkpatrick $\mathrm{CH}$ : Immunologic aspects of renal homotransplantation. In Starzl TE (ed): Experience in Renal Transplantation. Philadelphia, WB Saunders, 1964, pp 239-261

65. Zeevi A, Duquesnoy R, Eiras G, et al: Immunosuppressive effect of FK506 on in vitro lymphocyte alloactivation: Synergism with cyclosporine A. Transplant Proc 19(Suppl 6):40-44, 1987

Address reprint requests to

Jorge Reyes, MD

University of Pittsburgh

Pittsburgh Transplantation Institute

3601 Fifth Avenue 4C Falk Clinic

Pittsburgh, PA 15213 